\title{
GC 2012-5605: COURSE ASSESSMENT; A CONSISTENT MODEL
}

\section{Dr. Sabah Razouk Abro, Lawrence Technological University}

Dr. Sabah Abro is an internationally educated math professor and program Director at Lawrence Technological University. He graduated with a Bachelor degree from the University of Baghdad, pursued a post graduate diploma in planning from the United Nations institute in the middle east, Went to Wales in the United kingdom to get his Master's degree and then to Belgium for his Ph.D. He has also international work experience; he served as Faculty at Al Mustansiria University in Baghdad, a regional consultant at the Arab Institute for Statistics, a position that enabled him to lecture in a number Arab countries. Sabah has over 25 years of experience in higher education including more than 15 years in education management across different parts of the world. Concentration in the last 15 years was on development of career, Art \& Science, technology and engineering programs.

Leading positions in educational institutions including chair of department, acting Dean, university board member, University assessment committee member, consultant and team leader.

A unique experience in coordination between educational institution and industrial partners to build new paradigm in education through an NSF sponsored program.

Many years of in-depth experience in curriculum development. Extensive knowledge in academic programs, professional development programs and on the job training plans. Motivated, fluent in English with multi-lingual capability, internationally educated professional, with work experience in different countries and international organizations. Highly diversified, personable and outreaching communication skills.

\section{Mr. Jerry Cuper, Lawrence Technological University}

Jerry Cuper is a professor and advisor in the Department of Engineering Technology in the College of Engineering. His education includes graduate and undergraduate degrees, and completion of a technology apprenticeship program. Mr. Cuper's career has spanned a wealth of experience in the machine shop, on the drawing board, in construction, and many years in engineering design, testing and development, management, and planning. Most of his career was with the Ford Motor Company. Mr. Cuper's last assignment was managing the Ford Technology Review Center to help implement suppliers' new technologies. He developed and led the implementation of a new supplier process to dramatically change the way supplier technologies were integrated into Ford products. This supported Ford's vision to change from being a fast follower to being a leader in technology. Mr. Cuper developed the first-production automotive application of Graphite Fiber Reinforced Plastic; this bracket was given the Materials Engineering "Award of Merit". Cuper has taught courses in engineering and business at Lawrence Tech evening programs as an adjunct instructor since 1978. He has demonstrated the ability to work extremely well with students to focus their efforts on academic achievement and long-term career goals. Mr. Cuper's passion is muscle cars. He has owned 20 Mustangs over the years, starting with the $19652+2$ Fastback,now has a 2010 GT convertible, and is ordering his 21 st - 2013. 
Course Assessment; A consistent Model

\section{Abstract}

In the last decade or so educational goals assessment was the center of attention in many higher education institutions. Accreditation agencies like the Higher Learning Commission (HLC) and Accreditation Board for Engineering and Technology (ABET) are among a larger spectrum of entities demanding assessment should not only be part of the educational programs management process, but it should also be part of a more comprehensive process, which is the continuous improvement.

Based on these facts, a need for developing a consistent model in the assessment at the course level is highly needed. This model should map course assessment to the program learning outcomes and ultimately to the university educational goals because it is an important stage in the whole assessment process.

This paper is intended to present a methodology of assessing program learning outcomes through assessing the course learning objectives.

Teaching course by objectives has gained momentum in the twenty first century; it has proven beneficial to the students, instructors and the educational process at large.

We will show that the assessment of a well defined set of course learning objectives will provide a reliable source of program learning outcomes evaluation if they are mapped properly.

The conventional course evaluation that most institutions distribute at the end of each semester does not provide indices for success or failure to achieve the educational goals or program learning outcomes. It does, however, give indications about a set of information that cannot be considered a model of assessment.

The model that we have designed and used for three semesters has two methods of assessing course learning objectives: direct and indirect.

The direct assessment is conducted by the instructor where he or she will set up the level of achievement that is designed for each objective. Then the instructor will get feedback on the level of achievement based on the test, assignments and projects results meant to assess the level of achievement of the particular objective. This process will be an ongoing process throughout the semester where the final actual level of achievements will be compared with the desired level set by the instructor at the beginning of the semester. The negative or positive deviation from the target score of achievement per objective is then used to analyze the learning process and identify means and methods to improve or maintain the target achievement. 
The indirect part is the student's contribution to the assessment model, where students will rank the achievement of the same learning objectives from their prospective.

The model will easily pinpoint if there is any inconsistency in the assessment, for the results from both direct and indirect sources should provide the same picture and level of achievement within statistically accepted differences.

Any significant deviation from consistency is an indication of a serious problem in the course structure and probably methods of delivery that should be dealt with at the department level.

The paper will discuss the process of the successful writing of measurable learning objective. We will introduce statistical analysis of results from selected course assessments.

We will argue that this assessment process could lead to continuous improvement process if it is properly integrated in the plan of improvement.

The paper will also discuss the mapping of course learning objectives to the program learning objectives and university goals

\section{Teaching by Measurable Objectives}

Teaching by objectives is a delivery method that has proven effective over the years. Many programs, department and colleges do attach objectives to their curriculum, programs, plans of work, course descriptions and syllabi. Many of these objectives are general and sometime vague because they do not express measurability of success of these objectives. Examples of these objectives are: The student will understand..., the student will be familiar with..., the student will acquire knowledge of... and so on.

These types of "Course Learning objectives" have three major deficiencies; the first is generality where the objective is so general that could be used for almost any other course even from different level or knowledge area, the second is there is no indication of the skill to be acquired, and the third is that no measurement tool could be used to assess the achievement of the objectives and to compare performance of different groups.

Good leaning objectives for a course should be written in a way that expresses clearly the skills to be built through the course and the measurability of these skills. The objectives should clearly describe what the student will be able to do as a result of the learning experience of this course. These objectives should be lined up with other course learning objectives to the degree (program) learning outcomes. 
Once the objectives are written properly, the mastery target should be set for each objective of the course based on the importance of the objective to the course and to the program. Mastery, in our opinion, is anything above $80 \%$, yet there are some instructors who set $75 \%$ as the target for some of their Course Learning Objectives.

\section{The Assessment Model}

The Assessment Model of Course Learning Objectives that we are introducing consists of two different tools, these are:

\subsection{Direct assessment tools:}

Each course in the educational program has to have several objectives that are linked to the Degree Program Educational Learning Outcomes. The instructors set up the mastery bar for each objective using statistical indicator which is normally a percentage. The objectives are directly tested through student's evaluation tools such as exams, projects, homework. Each instructor is to calculate the average performance of the class towards each objective and record the data.

Some of the objectives could be accessed through more than one evaluation tool or could be assessed more than once. The instructor will average the data by objective and record it. At the end of the semester instructors will statistically summarize data in a table that shows the objectives, the link to the Program Learning Outcomes, the target achievement per objective and the actual achievement of the class by objective. The assessment at the program level will use data provided by instructors, tabulate them in a template that will generate statistical indicators like the deviation from the target, the overall mean performance and the standard deviations of the scores.

These statistical indicators will be analyzed by instructors so they can create an action plan to close the loop of the deficiency, if required, to satisfy the target for each objective. The department will use these tools from different classes to assess the overall department objectives.

The data collecting worksheet template is presented below: 


\begin{tabular}{|c|c|c|c|c|c|c|c|c|c|c|}
\hline & \multicolumn{4}{|c|}{ Course name and Number: } & & & & \multicolumn{3}{|c|}{ Semester and Year: } \\
\hline & Outcomes & Target & & & \multicolumn{3}{|c|}{ Assessment tools } & & & \\
\hline $\begin{array}{c}\text { Course learning objectives } \\
\text { ( please write your objectives below) }\end{array}$ & $\mathrm{A}-\mathrm{K}$ & score & $\mathrm{T} 1$ & $\mathrm{~A} 1$ & $\mathrm{~T} 2$ & T3 & A3 & Final & Mean & Deviation from Target \\
\hline 1 & $A B F$ & $80 \%$ & & & & & & & & $80 \%$ \\
\hline 2 & ECD & $80 \%$ & & & & & & & & $80 \%$ \\
\hline 3 & $A B F$ & $85 \%$ & & & & & & & & $85 \%$ \\
\hline 4 & GHE & $80 \%$ & & & & & & & & $80 \%$ \\
\hline 5 & AFE & $80 \%$ & & & & & & & & $80 \%$ \\
\hline 6 & $A C D$ & $85 \%$ & & & & & & & & $85 \%$ \\
\hline Mean & & & & & & & & & & \\
\hline Standard deviation & & & & & & & & & & \\
\hline Action to be taken: & & & & & & & & & & \\
\hline 1 & & & & & & & & & & \\
\hline 2 & & & & & & & & & & \\
\hline 3 & & & & & & & & & & \\
\hline
\end{tabular}

Note: As we all know the different objectives are assessed in different tests. So you do not have all the boxes filled in in one test. What you have to fill are the columns $\mathrm{D}$ through $\mathrm{H}$ if you need more than these columns please insert as needed.

The lines to be fills are those corresponding to objectives only. The last to lines are formulas and will appear automatically.

\subsection{Indirect assessment tools:}

Students in all courses are asked to complete a questionnaire about the course that they are about to finish. The questionnaire includes direct questions about the objectives and how do they evaluate the achieving of those objectives at the end of the semester. The students will be asked to rank the achievement of all Course Learning Objectives. The department will summarize and analyze the results of these questionnaires and discuss them on two levels: Level one is with instructor to test the conformance of these results with the direct assessment method and Level two is to compare these findings with the statistical indicators generated from direct assessment. The 
questionnaire produces the following summary statistical table for each course in the program:

\begin{tabular}{|c|c|c|c|c|c|c|}
\hline \multicolumn{2}{|l|}{ Course: } & \multicolumn{2}{|l|}{ Semester: } & \multicolumn{3}{|c|}{ Instructor: } \\
\hline & & Rating & $\mathrm{g}$ of the 0 & tives summ & & \\
\hline $\begin{array}{l}\text { Course } \\
\text { Learning } \\
\text { Objectives }\end{array}$ & $\begin{array}{l}5 \\
\text { (achieved) }\end{array}$ & 4 & 3 & $\begin{array}{l}1 \text { (Poorly } \\
\text { achieved) }\end{array}$ & Total & $\begin{array}{l}\text { Weighted } \\
\text { average }\end{array}$ \\
\hline 1 & & & & & & \\
\hline 2 & & & & & & \\
\hline 3 & & & & & & \\
\hline 4 & & & & & & \\
\hline Total & & & & & & \\
\hline $\begin{array}{l}\% \text { of the } \\
\text { class }\end{array}$ & & & & & & \\
\hline
\end{tabular}

The direct and indirect indicators will be used to finalize the action plan of closing the loop proposed by the instructor.

\section{Assessment statistics}

\section{1: Coverage of data}

We are going to introduce and analyze data collected from one semester and involve a total of 9 direct course assessment results and 9 indirect course assessments results.

The selected courses are from all levels, freshman, sophomore, junior and senior as distributed in the following table.

Table1: Course chosen for the study distributed by course level.

\begin{tabular}{|c|c|c|c|c|c|c|c|c|c|c|c|}
\hline & \multicolumn{4}{|c|}{ Direct } & & \multicolumn{4}{|c|}{ Indirect } & & \\
\hline Semester & Freshman & Sphomore & Junior & Senior & & Freshman & Sphomore & Junior & Senior & & tal \\
\hline \begin{tabular}{|l} 
Spring 2011 \\
\end{tabular} & 1 & 4 & to & 2 & 2 & & 4 & & 2 & 2 & 18 \\
\hline
\end{tabular}




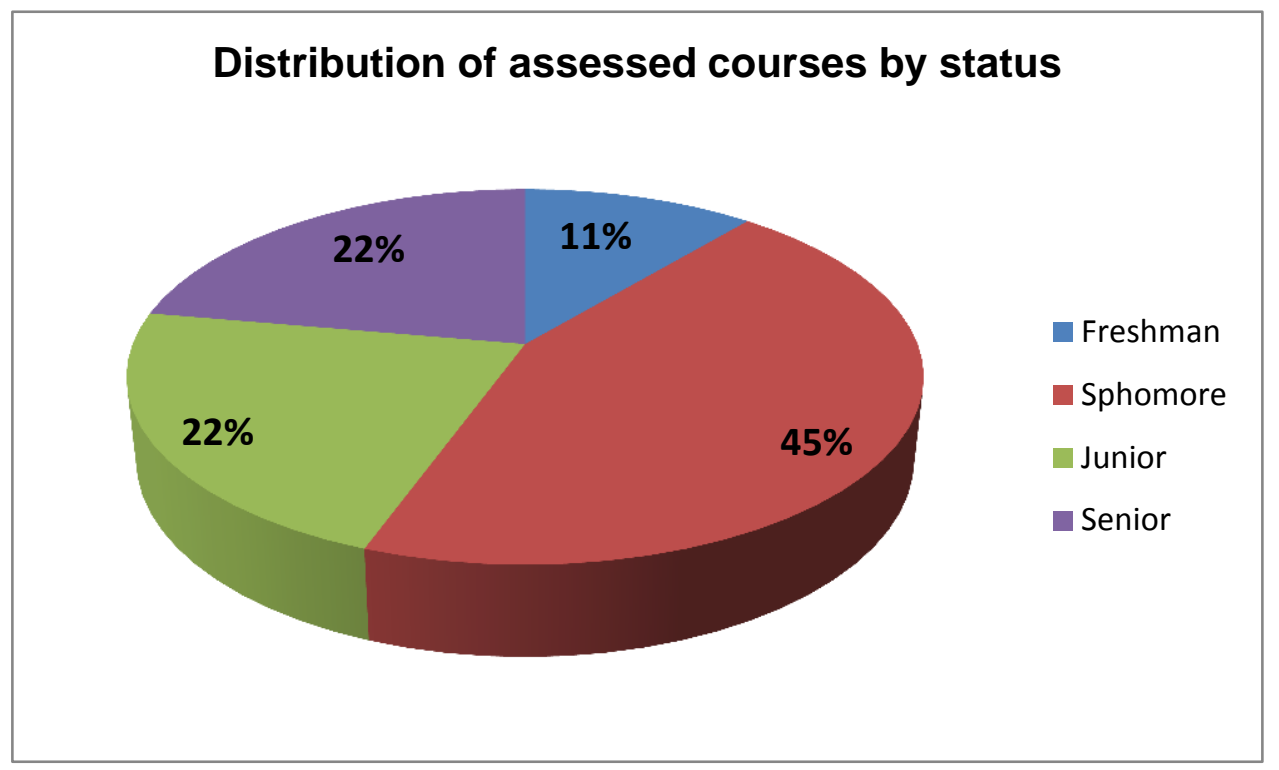

\section{2: Direct assessment data}

The data from 9 courses were summarized and grouped in the following two tables; the first one represents the conclusions from the freshman sophomore courses as far as the final score and the deviation from target are concerned, while the second contains the same data for the junior senior level of the courses.

Table 2: Outcome summary of the direct assessment for freshman/sophomore courses

\begin{tabular}{|c|c|c|c|c|c|c|c|c|c|c|}
\hline \multirow[b]{2}{*}{ Objective } & \multicolumn{2}{|c|}{ TME1023 } & \multicolumn{2}{|c|}{ MCS2023 } & \multicolumn{2}{|c|}{ TIE2063 } & \multicolumn{2}{|c|}{ TIE2093 } & \multicolumn{2}{|c|}{ MCS2323 } \\
\hline & score & deviation & score & deviation & score & deviation & score & deviation & score & deviation \\
\hline 1 & $82 \%$ & $61 \%$ & $88 \%$ & $8 \%$ & $98 \%$ & $18 \%$ & $96 \%$ & $21 \%$ & $78 \%$ & $3 \%$ \\
\hline 2 & $83 \%$ & $71 \%$ & $85 \%$ & $5 \%$ & $97 \%$ & $22 \%$ & $87 \%$ & $12 \%$ & $85 \%$ & $10 \%$ \\
\hline 3 & $82 \%$ & $74 \%$ & $87 \%$ & $7 \%$ & $100 \%$ & $25 \%$ & $88 \%$ & $8 \%$ & $82 \%$ & $7 \%$ \\
\hline 4 & $81 \%$ & $73 \%$ & $90 \%$ & $10 \%$ & $100 \%$ & $25 \%$ & $88 \%$ & $8 \%$ & $78 \%$ & $8 \%$ \\
\hline 5 & $91 \%$ & $91 \%$ & $84 \%$ & $4 \%$ & & & & & $82 \%$ & $7 \%$ \\
\hline 6 & $84 \%$ & $74 \%$ & $88 \%$ & $8 \%$ & & & & & $83 \%$ & $8 \%$ \\
\hline 7 & & & $85 \%$ & $5 \%$ & & & & & $78 \%$ & $3 \%$ \\
\hline 8 & & & $87 \%$ & $7 \%$ & & & & & $81 \%$ & $7 \%$ \\
\hline Average & $84 \%$ & $6 \%$ & $86.7 \%$ & $6.7 \%$ & $98.8 \%$ & $22.5 \%$ & $89.8 \%$ & $12.3 \%$ & $80.9 \%$ & $6.6 \%$ \\
\hline
\end{tabular}

Since the number of course learning objectives is different from course to course, we had to mark them with numbers instead of the actual words of the objective. This will not affect our general analysis attempt since the goal of the analysis is not the course content but the assessment results and the overall lesson learned from this exercise. 
The above data are represented in the following chart.

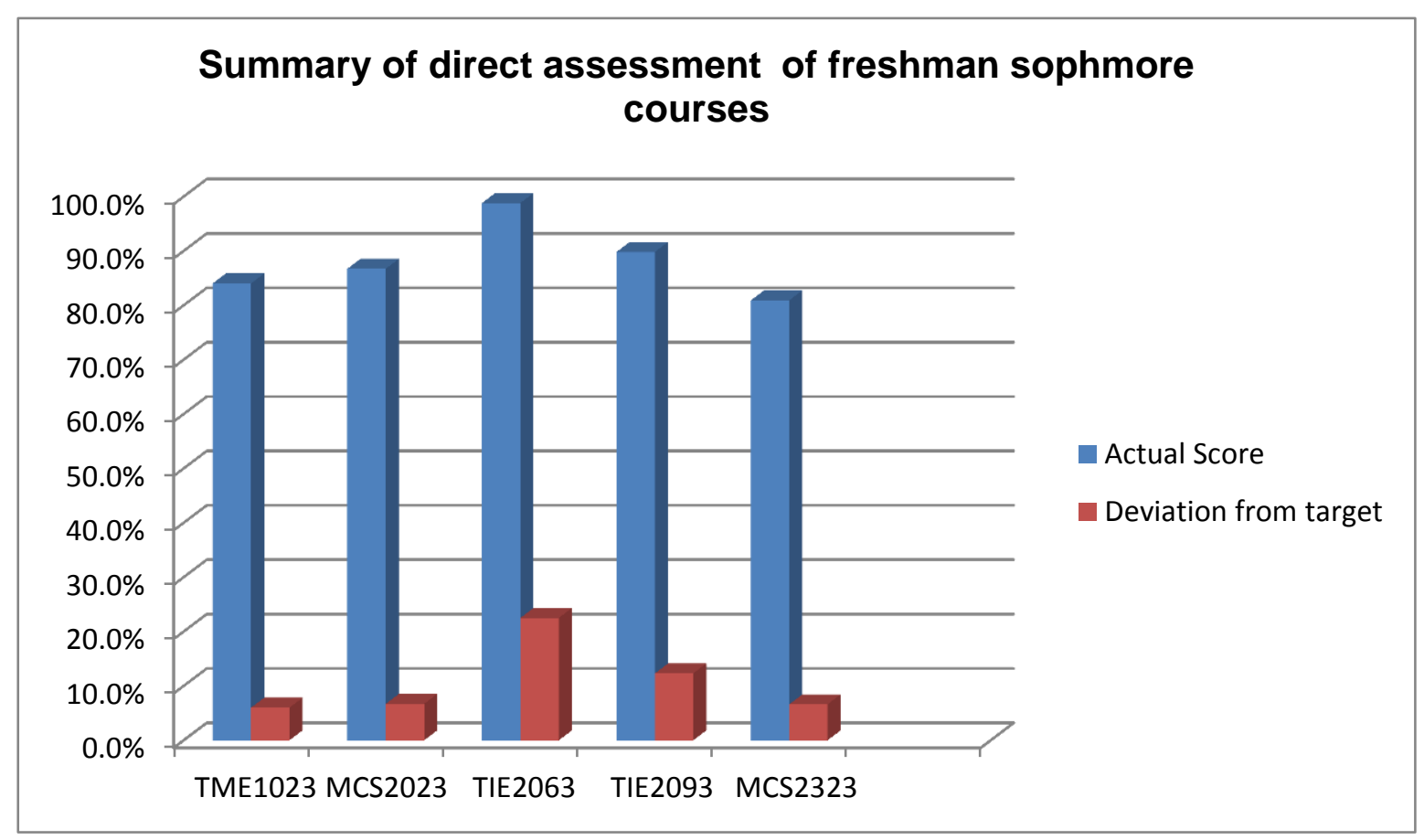

The general conclusion from the table and the data is that the target score for the objectives were generally met and exceeded in all the courses. A question could be raised when the actual score exceed the target score significantly, Such as in TIE20263 where the actual achievement exceeded the target by $22.5 \%$. The argument could be that either the target score does not reflect the level of mastery required or the test tools do not explore the missing skills of the students. It is recommended that when there is this kind of significant deviation from the target, whether the deviations is positive or negative, that the instructor should revisit the set of objectives, the delivery method and the student course work evaluation.

If after a series of thorough analysis, there was no deficiency discovered, the target score for the objectives should be moved up.

The other course that showed positive deviation of more than 10\% was TIE2093 where it indicated $12.3 \%$ above target achievement. This does not require from our point of view immediate alert and thorough investigation by the instructor as in the case of TIE2063 but it should raise a flag for monitoring the next assessment of the course, if the results are consistent, then moderate modifications of the objective and marginal adjustments to the target scores might be needed.

The other courses have exceeded the targets by $6-7 \%$ which in our point of view is good and reasonable. The communication with students about the course learning 
objective and the target score that should be met will help the students understand, appreciate and work to achieve the goals.

Table 3: Outcome summary of the direct assessment for junior/senior courses

\begin{tabular}{|c|c|c|c|c|c|c|c|c|}
\hline \multirow[b]{2}{*}{ Dbjective } & \multicolumn{2}{|c|}{ TME3113 } & \multicolumn{2}{|c|}{ TIE3163 } & \multicolumn{2}{|c|}{ TME4103 } & \multicolumn{2}{|c|}{ TIE4115 } \\
\hline & score & deviation & score & deviation & score & deviation & score & deviation \\
\hline 1 & $85 \%$ & $10 \%$ & $81 \%$ & $1 \%$ & $92 \%$ & $12 \%$ & $80 \%$ & $0 \%$ \\
\hline 2 & $85 \%$ & $10 \%$ & $77 \%$ & $2 \%$ & $91 \%$ & $16 \%$ & $77 \%$ & $2 \%$ \\
\hline 3 & $84 \%$ & $9 \%$ & $82 \%$ & $2 \%$ & $100 \%$ & $20 \%$ & $83 \%$ & $3 \%$ \\
\hline 4 & & & & & & & $78 \%$ & $3 \%$ \\
\hline 5 & & & & & & & $80 \%$ & $2 \%$ \\
\hline Average & $84.7 \%$ & $9.7 \%$ & $80.0 \%$ & $1.7 \%$ & $94.3 \%$ & $16.0 \%$ & $79.5 \%$ & $2.0 \%$ \\
\hline
\end{tabular}

The first general note that could be noticed is that the number of course learning objectives is less in junior/senior than those of freshman/sophomore courses. This could be due to the fact that the earlier courses in the curriculum are designed to build foundations in different knowledge areas.

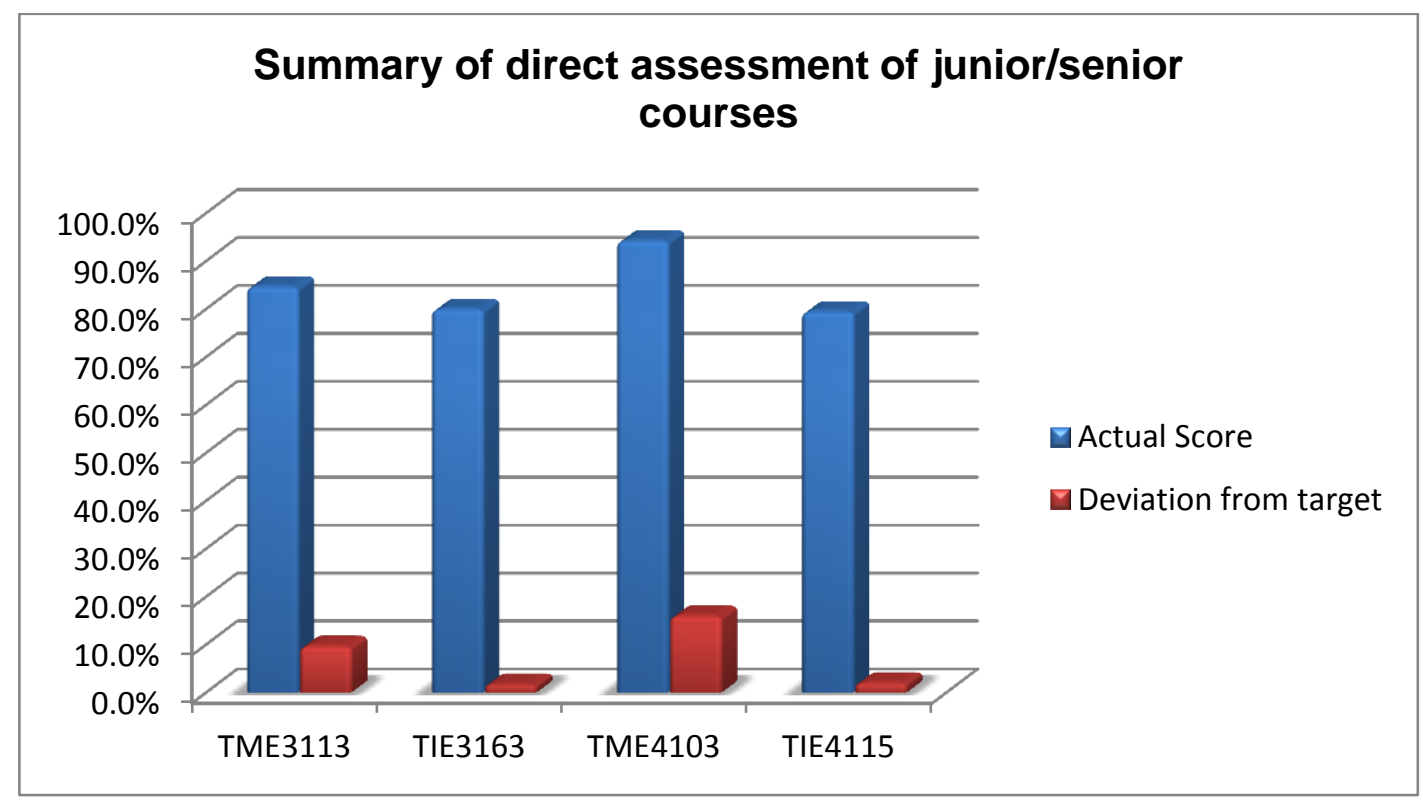

The junior /senior group of courses shows same pattern, one of junior and one of senior courses were $9.7 \%$ and $16 \%$ above target while the other were quite moderate in exceeding the target. The argument about TIE 2063 in the freshman/ 
sophomore group could be valid. We would even argue that as a senior class, if the objectives, the coverage, and the evaluation set of tools is equal for senior level then the target score should be moved up.

To have a general comparison between the two course levels we have calculated the averages of each group and present them in the following chart.

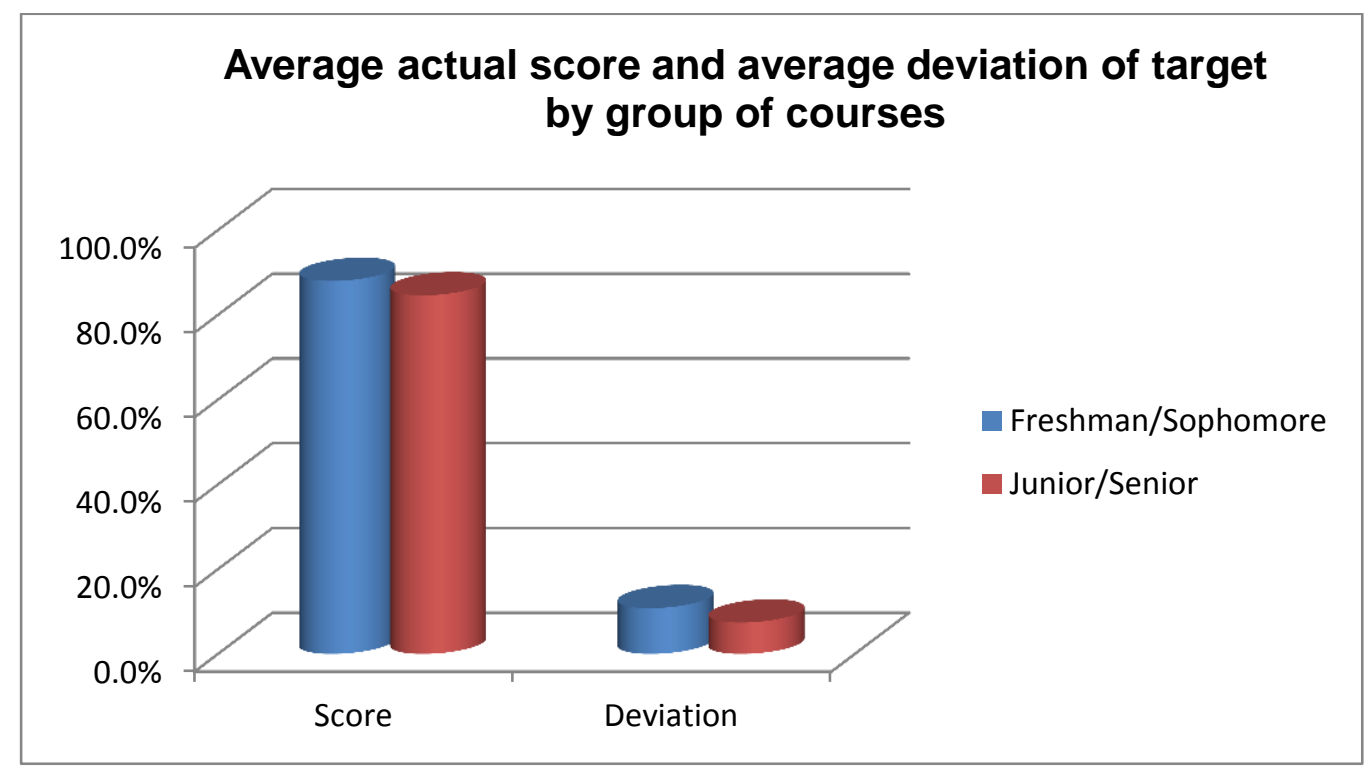

It is clear that the general picture shows that both the average actual scores and the average deviation were both higher for the freshman/ sophomore courses.

The overall actual average score by objective for the freshman/sophomore level was $88.0 \%$ while it was $84.6 \%$ for the junior/senior courses. The deviation from the target score averaged 10.8 above the target for the freshman/sophomore course while it averaged only $7.4 \%$ above target score for junior/senior courses.

\section{3: Indirect assessment data}

Since we are trying to analyze direct and indirect assessment results for consistency, we have collected data for the same nine courses that we have presented in 4.2.

The data in the tables four and five below represent the percentages of students ranking for each of the objectives. As we may notice from the table there are no ranking for any 
objective in all the assessed courses that is less than three which indicates that the objectives were reasonably met.

\begin{tabular}{|c|c|c|c|c|c|c|c|c|c|c|c|c|c|c|c|}
\hline \multirow[b]{3}{*}{ Objective } & & & & \multicolumn{12}{|c|}{ Table 4: Outcome summary of the indirect assessment for freshman/sophomore courses } \\
\hline & \multicolumn{3}{|c|}{ TME1023 } & \multicolumn{3}{|c|}{ MCS2023 } & \multicolumn{3}{|c|}{ TIE2063 } & \multicolumn{3}{|c|}{ TIE2093 } & \multicolumn{3}{|c|}{ MCS2323 } \\
\hline & 5 & 4 & 3 & 5 & 4 & 3 & 5 & 4 & 3 & 5 & 4 & 3 & 5 & 4 & 3 \\
\hline 1 & $100 \%$ & $0 \%$ & & $62 \%$ & $33 \%$ & $5 \%$ & $66.7 \%$ & $22.2 \%$ & $1.1 \%$ & $100 \%$ & & & $54 \%$ & $46 \%$ & \\
\hline 2 & $90 \%$ & $10 \%$ & & $62 \%$ & $33 \%$ & $5 \%$ & $55.6 \%$ & $44.6 \%$ & $0.0 \%$ & $80 \%$ & $20 \%$ & & $46 \%$ & $54 \%$ & \\
\hline 3 & $90 \%$ & $10 \%$ & & $67 \%$ & $28 \%$ & $5 \%$ & $66.7 \%$ & $33.3 \%$ & $0.0 \%$ & $80 \%$ & $20 \%$ & & $54 \%$ & $46 \%$ & \\
\hline 4 & $90 \%$ & $10 \%$ & & $56 \%$ & $28 \%$ & $16 \%$ & $66.7 \%$ & $22.2 \%$ & $1.1 \%$ & $40 \%$ & $60 \%$ & & $69 \%$ & $31 \%$ & \\
\hline 5 & $80 \%$ & $20 \%$ & & $56 \%$ & $28 \%$ & $16 \%$ & & & & & & & $62 \%$ & $31 \%$ & $7 \%$ \\
\hline 6 & & & & $62 \%$ & $22 \%$ & $17 \%$ & & & & & & & $46 \%$ & $46 \%$ & $8 \%$ \\
\hline 7 & & & & $62 \%$ & $33 \%$ & $5 \%$ & & & & & & & $54 \%$ & $39 \%$ & $7 \%$ \\
\hline 8 & & & & $67 \%$ & $28 \%$ & $5 \%$ & & & & & & & $69 \%$ & $31 \%$ & \\
\hline
\end{tabular}

5: Perfectly Met 4: Very well met $\quad$ 3: Reasonably met

The data show that the majority of the students do believe that the course learning objectives have been either perfectly met or very well met.

The chart below represents the percentages of the students who ranked meeting the objectives with four or five.

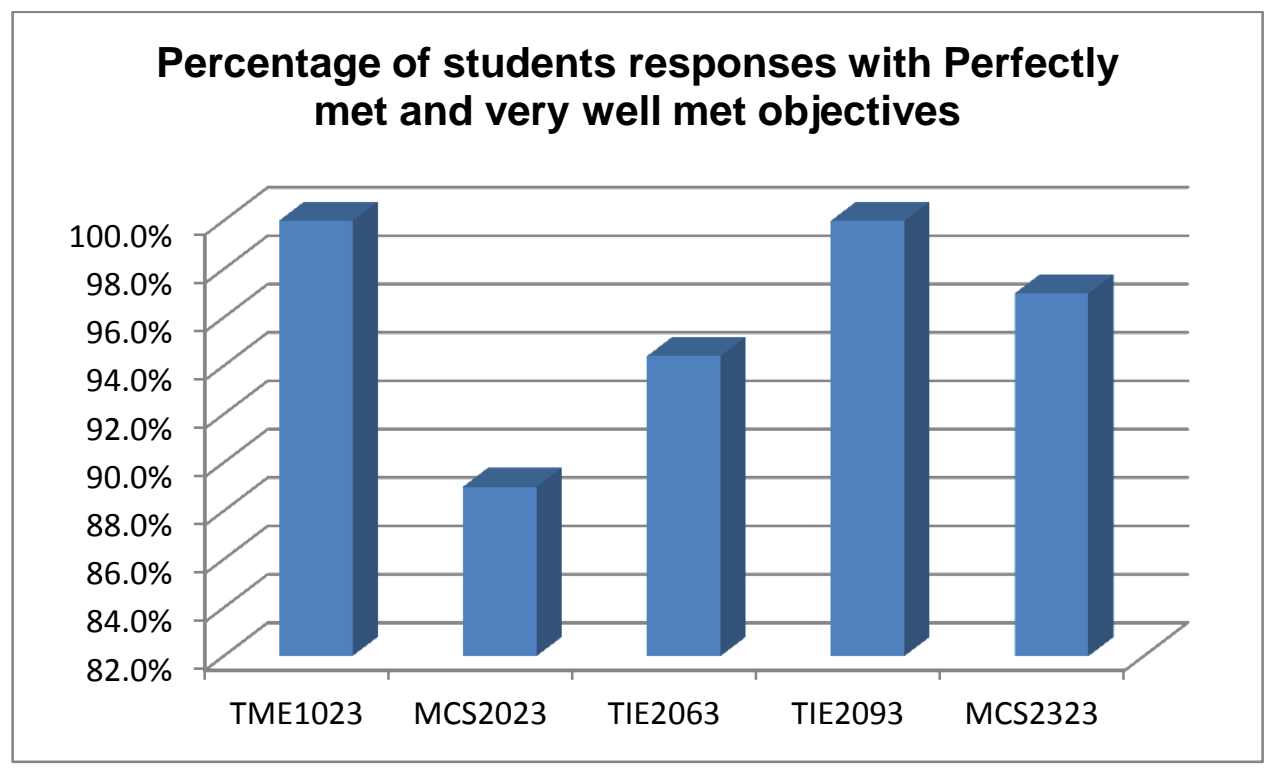


Although the percentages were $90 \%$ or more, it looks like MCS 2023 was the lowest of the freshman/sophomore group. Knowing this is a statistics course might explain that partially.

The only course that has all objectives ranked either perfectly met or very well met was TIE3163 in the junior/senior group of courses, the rest have some students ranking some objectives as reasonably met. These could be seen in table 5 .

Table 5: Outcome summary of the indirect assessment for freshman/sophomore courses

\begin{tabular}{|c|c|c|c|c|c|c|c|c|c|c|c|c|}
\hline & \multicolumn{3}{|c|}{ TME3113 } & \multicolumn{3}{|c|}{ "TIE3163 } & \multicolumn{3}{|c|}{ TME4013 } & \multicolumn{3}{|c|}{ TIE4115 } \\
\hline Objective & 5 & 4 & 3 & 5 & 4 & 3 & 5 & 4 & 3 & 5 & 4 & 3 \\
\hline 1 & $57.1 \%$ & $14.3 \%$ & $28.6 \%$ & $50.0 \%$ & $50.0 \%$ & & $80.0 \%$ & $10.0 \%$ & $10.0 \%$ & $78.1 \%$ & $18.8 \%$ & $3.1 \%$ \\
\hline 2 & $42.9 \%$ & $42.9 \%$ & $14.2 \%$ & $60.0 \%$ & $40.0 \%$ & & $70.0 \%$ & $20.0 \%$ & $10.0 \%$ & $78.1 \%$ & $27.9 \%$ & $0.0 \%$ \\
\hline 3 & $57.1 \%$ & $28.6 \%$ & $14.3 \%$ & $60.0 \%$ & $40.0 \%$ & & $90.0 \%$ & $10.0 \%$ & $0.0 \%$ & $56.3 \%$ & $40.6 \%$ & $3.1 \%$ \\
\hline 4 & & & & & & & & & & $75.0 \%$ & $21.8 \%$ & $3.2 \%$ \\
\hline 5 & & & & & & & & & & & & \\
\hline 6 & & & & & & & & & & & & \\
\hline 7 & & & & & & & & & & & & \\
\hline 8 & & & & & & & & & & & & \\
\hline
\end{tabular}

5: Perfectly Met 4: Very well met 3: Reasonably met

The percentages of ranks four and five varied between the four junior/ senior courses. It looks like students in senior courses believe that the objectives of their courses were almost perfectly met

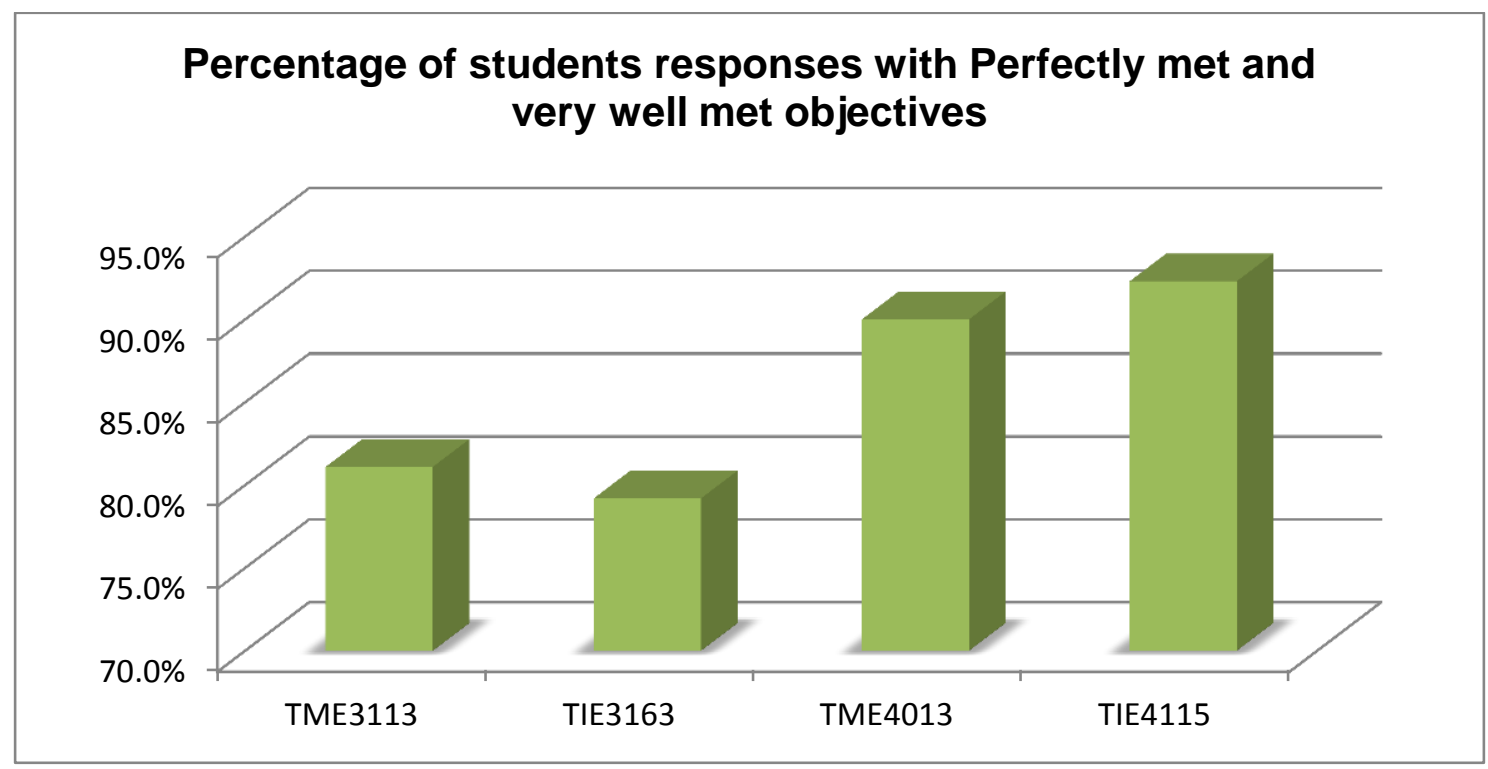




\section{4: Comparison between Direct and indirect data}

The assumption of the model is that if the delivery method, Course Learning Objectives, the students performance and the overall practice during the semester is positively serving the educational goal of the course and ultimately the program, then both assessment methods, the direct and the indirect should be consistent.

From the above data presentation and analysis, we can tell that in general there is harmony between results from both methods of assessing.

As indicated earlier, each set of data were collected differently. The direct assessment data reflect the average performance of students in their homework, assignments, quizzes and tests. The indirect assessment data represent ranking of the meeting of the learning objectives from the student's point of view. To come up with some statistical indicator that allows us to acquire some measurement that could be statistically comparable to the average performance in the direct assessment, we have calculated the weighted average of ranks by assuming that each rank represents a percentage of achievement. This means that rank five was treated as $100 \%$, rank 4 as $80 \%$ and rank 3 as $60 \%$. The weight for each rank was the number of students voting for this rank.

Table 6 contains the percentages from the direct assessment for all the objectives and the weighted average percentage of the student ranks for all the assessed nine courses.

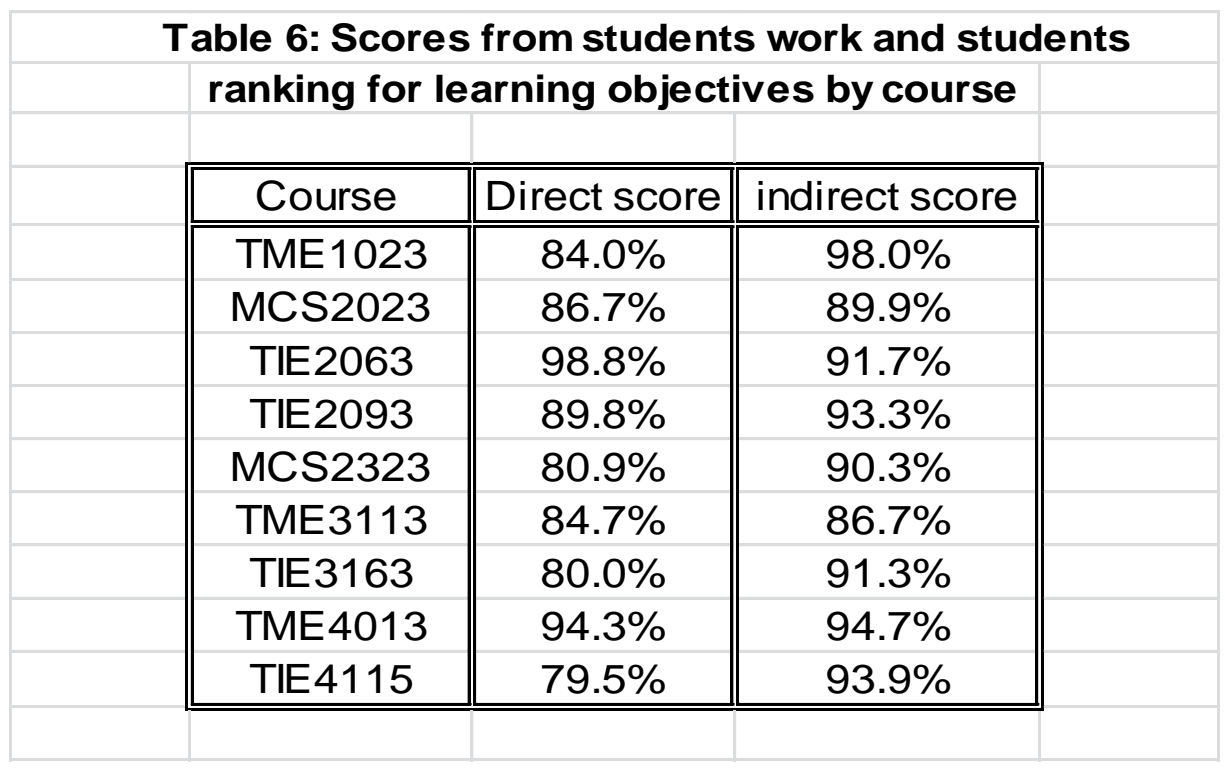


It should be noticeable from the table that the scores of the students reflects a higher level of achievement of the objectives from what their actual scores show. In some of the courses the difference are significantly higher from the direct data. The only departure from that fact is TIE2063 which happened to have a very high scores from the direct method. This fact aligns with our argument earlier about exceeding the target by $22.5 \%$.

The freshman/sophomore courses comparison are better explored in the chart below.

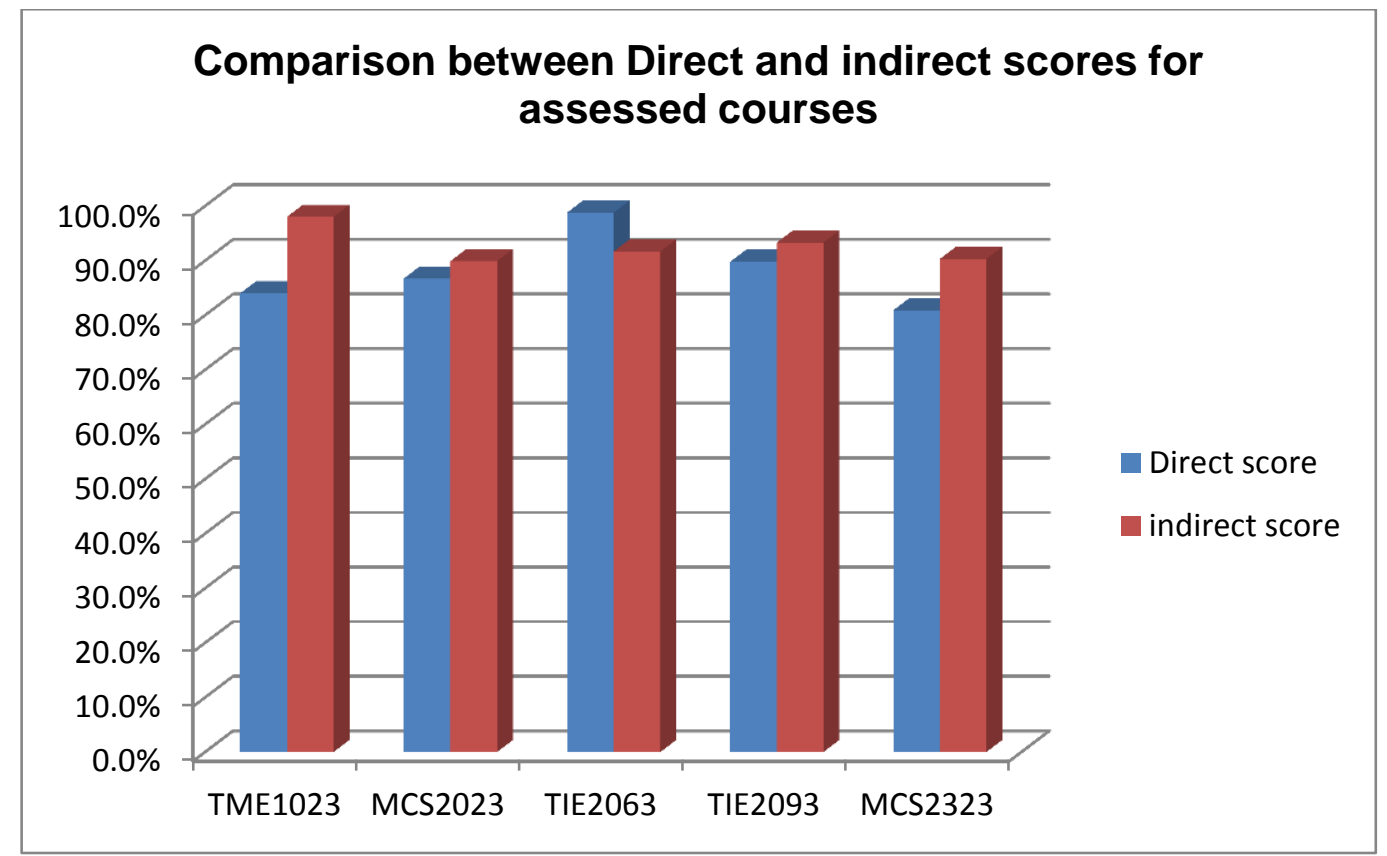

As for the junior/ senior level courses, the students scored the achievement of objectives significantly higher than what the direct assessment scores provided.

The most significant difference comes from TIE4115, the senior project five credit course. The students in this course do learn and practice how to solve real world problems. The course represents the highlight of the BSET program, which might be the reason for the students to rank it highly. 


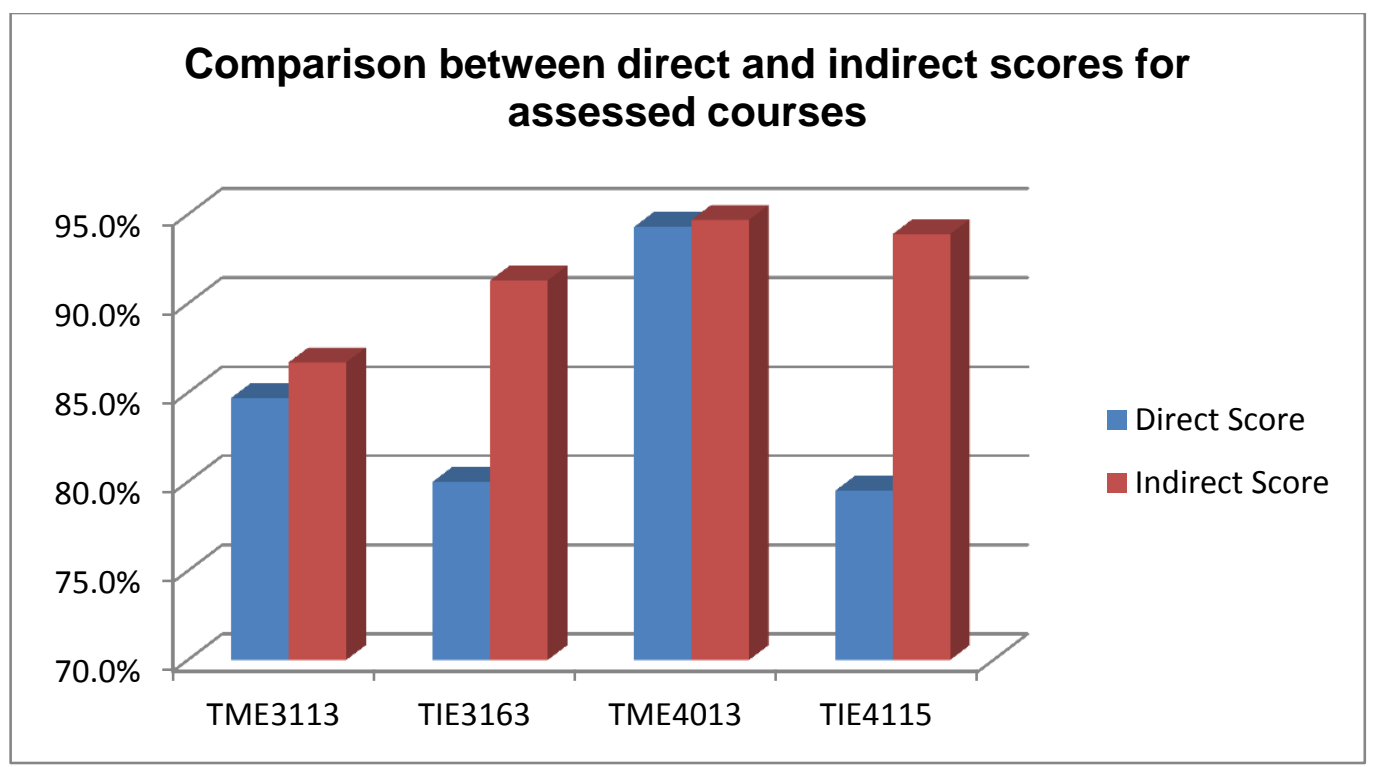

\section{5 : Conclusions and recommendations}

Our conclusions from the analysis of this model and related statistics are:

i. The model is a powerful tool that could help the instructor, the program and the department to capture major successes and failure in the delivery of a course.

ii. The model can be used to adjust the Course Learning Objective target, hence it helps improving the learning process.

iii. A repeated use of the model for the same courses could be a valuable tool in analysis of different instructors and different student group's performance.

That being said, we recommend a continuation of the study of the same courses assessment from different semester in the future. We believe that this comparative study will provide valuable data and will probably reveal some lessons that could be learned. 